\title{
Numerical Simulation of the Dissolution Process of GaSb into InSb Melt under Normal and Microgravity Conditions
}

\author{
By Youhei TAKAGI ${ }^{1)}$, Natsuki SUZUKI ${ }^{2)}$, Yasunori OKANO ${ }^{1)}$, Akira TANAKA ${ }^{3)}$, Yasuhiro HAYAKAWA ${ }^{3)}$ \\ and Sadik DOST ${ }^{4}$ \\ ${ }^{1)}$ Department of Materials Engineering Science, Osaka University, Toyonaka, Japan \\ ${ }^{2)}$ Department of Materials Science and Chemical Engineering, Shizuoka University, Hamamatsu, Japan \\ ${ }^{3)}$ Research Institute of Electronics, Shizuoka University, Hamamatsu, Japan \\ ${ }^{4)}$ Crystal Growth Laboratory, University of Victoria, Victoria, BC, Canada
}

(Received June 17th, 2011)

\begin{abstract}
Temperature Gradient Growth experiments of $\mathrm{In}_{x} \mathrm{Ga}_{1-x} \mathrm{Sb}$ will be performed on the International Space Station (ISS) in 2012. In the $\mathrm{GaSb} / \mathrm{InSb} / \mathrm{GaSb}$-sandwich system used, before growth, the dissolution process of GaSb into InSb takes place during the formation of the growth solution (melt). Solutal mass transport occurring during dissolution plays a significant role. In crystal growth on Earth, the large difference between the densities of InSb and $\mathrm{GaSb}$ leads to gravitational segregation in the melt and axial non-uniformity in crystal composition. In addition, the large separation between the liquidus and solidus curves in the phase diagram of this system further contributes to compositional non-uniformity. In order to have a better understanding for the effect of gravity on solutal transport during in this system, the dissolution process was numerically simulated under both Earth's gravity and a microgravity level on the ISS. Numerical simulations showed that under Earth's gravity, dissolution of the GaSb seed was enhanced due to the contribution of solutal natural convection. However, under microgravity diffusion mass transport was dominant in the melt, and the contribution of natural convection was not significant.
\end{abstract}

Key Words: Crystal Growth, Numerical Simulation, Gravity Segregation, Mass Transportation, Natural Convection

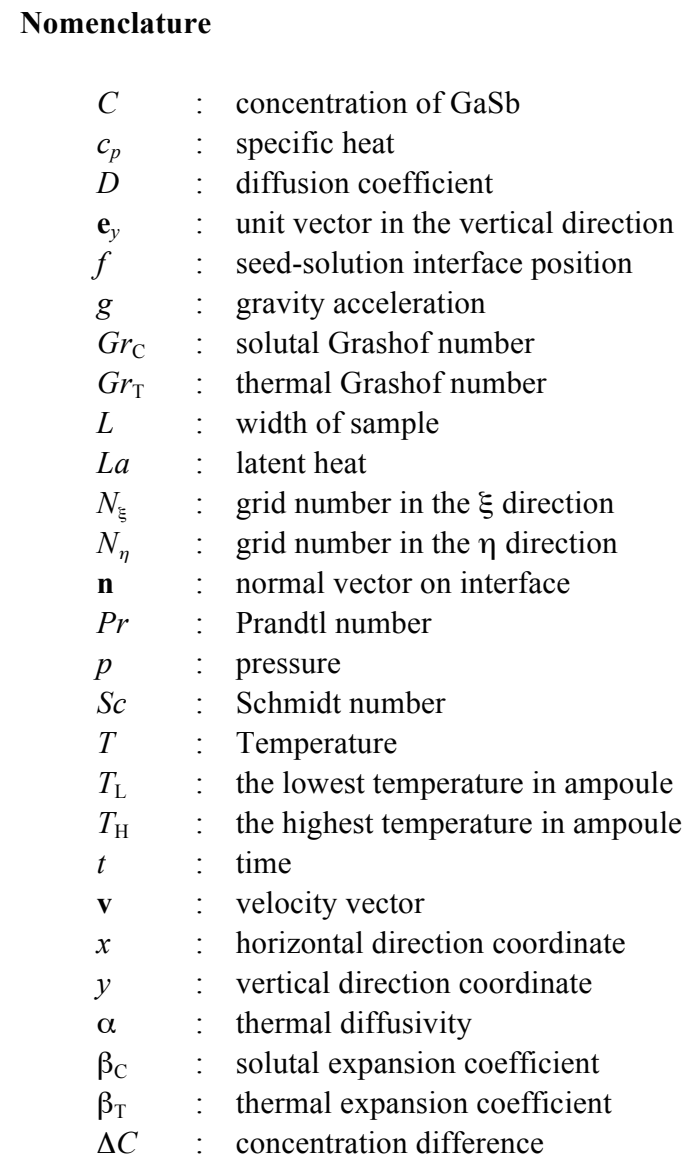

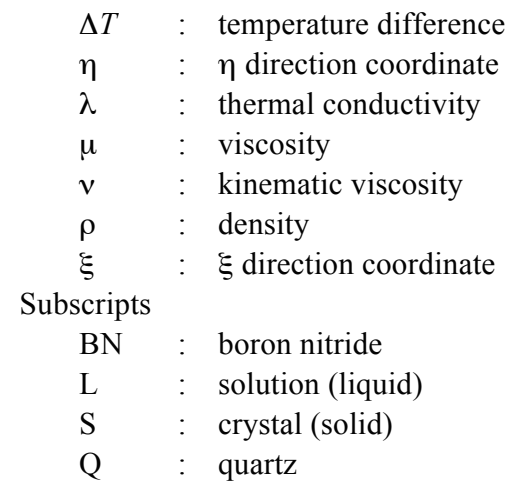

\section{Introduction}

$\mathrm{In}_{x} \mathrm{Ga}_{1-x} \mathrm{Sb}$ is a ternary compound semiconductor whose composition $(x)$ is adjustable. Thus, by adjusting its composition, the lattice constant can be varied between $6.09 \AA$ and $6.48 \AA$, and correspondingly the wavelength can be controlled between $1.7 \mu \mathrm{m}$ and $6.8 \mu \mathrm{m}^{1)}$. As the range of wavelength is mid-infrared, $\operatorname{In}_{x} \mathrm{Ga}_{1-x} \mathrm{Sb}$ can be used for various industrial applications including gas sensors and optoelectronic devices. Such applications require high quality bulk crystals of uniform compositions. However, it is difficult to grow such crystals on Earth due to the effect of gravity, which gives rise to density-driven thermosolutal convection in the melt ${ }^{2}$. Such convection leads to compositional fluctuations in the grown crystal and consequently degrades crystal 
quality $^{3)}$. In addition, segregation due to the large separation in the phase diagram leads to differences between the liquid (solution) and solid (grown crystal) compositions.

On a microgravity platform such as the ISS, however, these adverse effects related to thermosolutal convection and segregation may be minimized. In this direction, crystal growth experiments of $\mathrm{In}_{x} \mathrm{Ga}_{1-x} \mathrm{Sb}$ are scheduled to be performed on the ISS in 2012. There are two main objectives of these space experiments: a) First is to investigate the effects of natural convection and diffusion transport in the solution on crystal compositional uniformity; and b) the second is to examine and understand interface kinetics in crystal growth.

Preliminary experiments on Earth were performed previously ${ }^{3-7)}$. Rajesh et al. ${ }^{7)}$ carried out an in-situ observation of $\operatorname{In}_{x} \mathrm{Ga}_{1-x} \mathrm{Sb}$ crystal growth in a furnace with temperature gradient along the growth ampoule. In this experiment, a cartridge of $\mathrm{GaSb} / \mathrm{InSb} / \mathrm{GaSb}$ sandwich structure was used, and the dissolution process of $\mathrm{GaSb}$ was examined by the $\mathrm{X}$-ray penetration method ${ }^{6}$. When the cartridge is heated over the melting point of InSb, the InSb-melt was established in the middle region because the melting point of $\mathrm{InSb}$ is lower than that of GaSb. GaSb is dissolved into the InSb-melt from the high-temperature feed crystal, and $\mathrm{In}_{x} \mathrm{Ga}_{1-x} \mathrm{Sb}$ then grows on the low-temperature seed crystal. Although the dissolution length of $\mathrm{GaSb}$ was assumed to become large at the high-temperature feed, significant dissolution also occurred at the low-temperature seed. This was due to the effect of gravity on Earth giving rise to a significant contribution of convection to the dissolution process in this system, and, consequently, affecting the solute transport in the melt. The degree of this contribution can only be determined by making comparisons with the results of replica microgravity experiments on the ISS.

The growth process of InGaSb crystals by the temperature gradient method begins after the dissolution process of $\mathrm{GaSb}$ into the solution, and the initiation of the growth process depends on the saturation condition of the solution. As the In composition of the grown crystal changes in the axial direction due to effect of gravity ${ }^{1)}$, initial conditions of growth process, such as the position of GaSb crystal and the saturated state of solution, affect the crystal quality significantly. Thus, in this study, we have carried out numerical simulations for the dissolution process of $\mathrm{GaSb}$ into InSb melt under normal and microgravity conditions prior to the scheduled spaced experiments on the ISS.

\section{Analysis model}

\subsection{Numerical model}

A schematic description of the GaSb dissolution system is shown in Fig. 1. The $\mathrm{GaSb} / \mathrm{InSb} / \mathrm{GaSb}$ sandwich sample is stacked in an ampoule as shown in Fig. 1(a). The system is subject to a temperature gradient in the axial direction being hotter at the top. The bottom of the GaSb seed is heated from $519^{\circ} \mathrm{C}$ to $650^{\circ} \mathrm{C}$ and the top of the $\mathrm{GaSb}$ feed from $533^{\circ} \mathrm{C}$ to $664^{\circ} \mathrm{C}$ (Fig. 2(b)). As the melting points of InSb and $\mathrm{GaSb}$ are $525^{\circ} \mathrm{C}$ and $712^{\circ} \mathrm{C}$, respectively, InSb melts first during the heating period. Once the furnace reaches the intended temperature profile, the profile is then maintained at the constant temperature gradient of $1.0^{\circ} \mathrm{C} / \mathrm{mm}$.

The boundary condition used for temperature in this model is slightly different from that of the previous experiment ${ }^{7)}$ since the temperature on the outer edge of the ampoule could not have been controlled in the experiment. The related physical properties of $\operatorname{In}_{x} \mathrm{Ga}_{1-x} \mathrm{Sb}, \mathrm{GaSb}, \mathrm{BN}$ and quartz ${ }^{9,10)}$ are

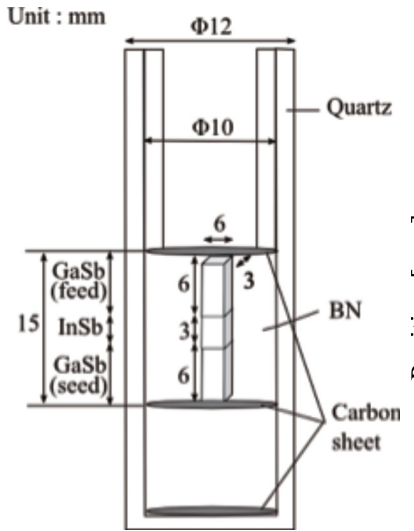

(a)

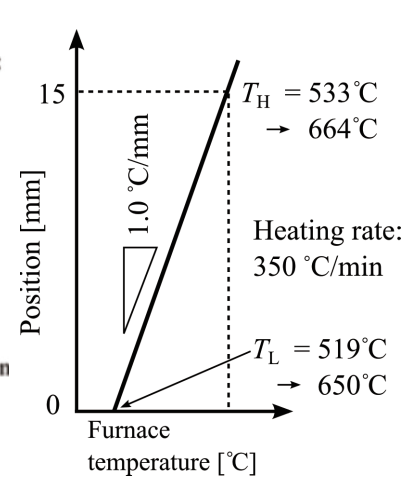

(b)
Fig. 1. Schematic description of the GaSb dissolution experiment: (a) ampoule configuration, (b) temperature gradient in crystals ${ }^{8)}$.

\begin{tabular}{lcc}
\multicolumn{3}{c}{ Table 1. Physical properties of InGaSb (solution) ${ }^{9,10)}$} \\
\hline Property & Symbol & Value \\
\hline Thermal conductivity & $\lambda_{\mathrm{L}}[\mathrm{W} /(\mathrm{m} \cdot \mathrm{K})]$ & 17 \\
Density & $\rho_{\mathrm{L}}\left[\mathrm{kg} / \mathrm{m}^{3}\right]$ & 6300 \\
Specific heat & $c_{p, \mathrm{~L}}[\mathrm{~J} /(\mathrm{kg} \cdot \mathrm{K})]$ & 300 \\
Viscosity & $\mu[\mathrm{Pa} \cdot \mathrm{s}]$ & $1.1 \times 10^{-6}$ \\
Thermal diffusivity & $\alpha_{\mathrm{L}}\left[\mathrm{m}^{2} / \mathrm{s}\right]$ & $9.0 \times 10^{-6}$ \\
Diffusion coefficient & $D\left[\mathrm{~m}^{2} / \mathrm{s}\right]$ & $1.2 \times 10^{-8}$ \\
Kinematic viscosity & $v\left[\mathrm{~m}^{2} / \mathrm{s}\right]$ & $1.7 \times 10^{-7}$ \\
Thermal expansion coefficient & $\beta_{\mathrm{T}}[1 / \mathrm{K}]$ & $1.0 \times 10^{-4}$ \\
Solutal expansion coefficient & $\beta_{\mathrm{C}}[-]$ & 0.05 \\
\hline
\end{tabular}

\begin{tabular}{|c|c|c|}
\hline Property & Symbol & Value \\
\hline Thermal conductivity & $\lambda_{\mathrm{S}}[\mathrm{W} /(\mathrm{m} \cdot \mathrm{K})]$ & 6.4 \\
\hline Density & $\rho_{\mathrm{s}}\left[\mathrm{kg} / \mathrm{m}^{3}\right]$ & 5600 \\
\hline Specific heat & $c_{p, \mathrm{~S}}[\mathrm{~J} /(\mathrm{kg} \cdot \mathrm{K})]$ & 300 \\
\hline Thermal diffusivity & $\alpha_{\mathrm{S}}\left[\mathrm{m}^{2} / \mathrm{s}\right]$ & $3.8 \times 10^{-6}$ \\
\hline Latent heat & $L a[\mathrm{~J} / \mathrm{kg}]$ & $3.14 \times 10^{5}$ \\
\hline
\end{tabular}

\begin{tabular}{lcc}
\multicolumn{3}{c}{ Table 3. Physical properties of $\mathrm{BN}^{10)}$} \\
\hline Property & Symbol & Value \\
\hline Thermal conductivity & $\lambda_{\mathrm{BN}}[\mathrm{W} /(\mathrm{m} \cdot \mathrm{K})]$ & 30.0 \\
Density & $\rho_{\mathrm{BN}}\left[\mathrm{kg} / \mathrm{m}^{3}\right]$ & 1900 \\
Specific heat & $c_{p, \mathrm{BN}}[\mathrm{J} /(\mathrm{kg} \cdot \mathrm{K})]$ & 1850 \\
Thermal diffusivity & $\alpha_{\mathrm{BN}}\left[\mathrm{m}^{2} / \mathrm{s}\right]$ & $8.5 \times 10^{-6}$ \\
\hline
\end{tabular}

\begin{tabular}{lcc}
\multicolumn{3}{c}{ Table 4. Physical properties of quartz ${ }^{10)}$} \\
\hline Property & Symbol & Value \\
\hline Thermal conductivity & $\lambda_{\mathrm{Q}}[\mathrm{W} /(\mathrm{m} \cdot \mathrm{K})]$ & 2.2 \\
Density & $\rho_{\mathrm{Q}}\left[\mathrm{kg} / \mathrm{m}^{3}\right]$ & 2200 \\
Specific heat & $c_{p, Q}[\mathrm{~J} /(\mathrm{kg} \cdot \mathrm{K})]$ & 1000 \\
Thermal diffusivity & $\alpha_{\mathrm{Q}}\left[\mathrm{m}^{2} / \mathrm{s}\right]$ & $1.0 \times 10^{-6}$ \\
\hline
\end{tabular}


given in Tables 1,2, 3 and 4, respectively. Although the $\mathrm{In}_{x} \mathrm{Ga}_{1-x} \mathrm{Sb}$ solution is formed after the dissolution of $\mathrm{GaSb}$ into the InSb melt ${ }^{8)}$ and the solution components ratio changes with time, constant physical properties of $\operatorname{In}_{0.5} \mathrm{Ga}_{0.5} \mathrm{Sb}$ solution were used in the simulations for simplicity.

\subsection{Numerical method}

The following assumptions were made in the model: the liquid phase $\left(\mathrm{In}_{0.5} \mathrm{Ga}_{0.5} \mathrm{Sb}\right)$ is an incompressible, Newtonian fluid, and the Boussinesq approximation holds. Under these assumptions, the dimensionless governing equations of the liquid phase take the following forms:

Continuity:

$$
\nabla \cdot \mathbf{v}=0
$$

Momentum:

$$
\frac{\partial \mathbf{v}}{\partial t}+(\mathbf{v} \cdot \nabla) \mathbf{v}=-\nabla p+\nabla^{2} \mathbf{v}+G r_{\mathrm{T}} T \mathbf{e}_{y}+G r_{\mathrm{C}} C \mathbf{e}_{y}
$$

Energy:

$$
\frac{\partial T}{\partial t}+(\mathbf{v} \cdot \nabla) T=\frac{1}{P r} \nabla^{2} T
$$

Mass transport (for $\mathrm{GaSb}$ concentration):

$$
\frac{\partial C}{\partial t}+(\mathbf{v} \cdot \nabla) C=\frac{1}{S c} \nabla^{2} C
$$

In the solid phases (crystals, and ampoule wall), heat conduction is the only governing equation:

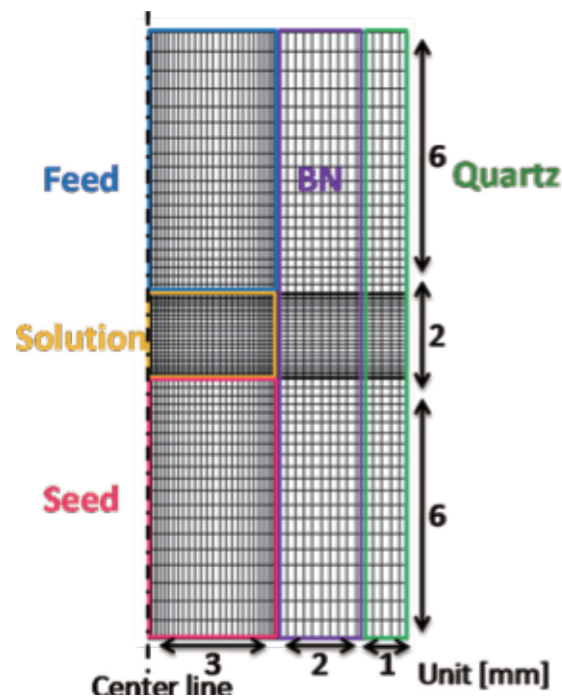

Fig. 2. Computational grid of the two-dimensional axisymmetric model.

\begin{tabular}{lcc}
\multicolumn{3}{c}{ Table 5. The number of numerical grid. } \\
\hline Region & $N_{\xi}$ & $N_{\eta}$ \\
\hline Seed/feed crystal & 81 & 81 \\
Solution & 81 & 81 \\
BN & 41 & 201 \\
Quartz & 21 & 201 \\
\hline
\end{tabular}

$$
\frac{\partial T}{\partial t}=\frac{1}{\operatorname{Pr}} \frac{\alpha_{\mathrm{S}}}{\alpha_{\mathrm{L}}} \nabla^{2} T
$$

The above governing equations were discretized by the finite volume method in a boundary fitted coordinate system to capture the interface change between the liquid and the solid phases, and were solved by the SIMPLE algorithm. The computational grid is shown in Fig. 2 and the numbers of grid in each region are given in Table 5. The height of the $\mathrm{In}_{x} \mathrm{Ga}_{1-x} \mathrm{Sb}$ solution was smaller than that of the experimental InSb material block shown in Fig. 1(a) because the simulation started from the melting of InSb and the volume change from solid to liquid was considered. The computational domain was taken as axisymmetric (2-D), and the grid was clustered near the solid-liquid interface. Since the melt-crystal interface was curved during the dissolution process, the coordinate transformation was introduced in the present simulation code. The boundary fitted coordinates $(x, y)$ of the physical space (Fig. 3(a)) were transformed into the orthogonal equally-spaced coordinates $(\xi, \eta)$ in the computational space (Fig. 3(b)). Then, all the governing equations were transformed by Jacobian

$$
J=\frac{\partial x}{\partial \xi} \frac{\partial y}{\partial \eta}-\frac{\partial x}{\partial \eta} \frac{\partial y}{\partial \xi}
$$

For example, the derivative of a scalar $\phi$ is calculated by the chain rule as

$$
\frac{\partial \phi}{\partial x}=\frac{1}{J}\left(\frac{\partial y}{\partial \eta} \frac{\partial \phi}{\partial \xi}-\frac{\partial y}{\partial \xi} \frac{\partial \phi}{\partial \eta}\right)
$$

Other operators for scalars and vectors were calculated similarly by using the Jacobian and metrics. As the interface moved temporally during the dissolution process, the grid spacing gradually changed and the Jacobian and metrics were calculated at each time step.

At the interface between the solution and the seed, the

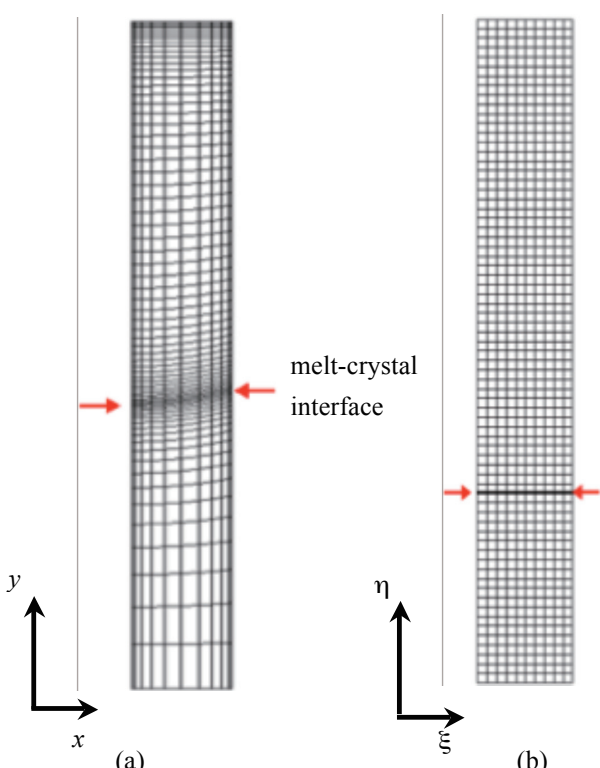

Fig. 3. Coordinate transformation of the boundary fitted coordinate method: (a) physical space, (b) computational space. 
following balance equations were considered to compute the interface position:

Energy balance:

$$
\rho_{\mathrm{S}} L\left(\mathbf{n} \cdot \mathbf{e}_{y}\right)=\lambda_{\mathrm{S}}(\mathbf{n} \cdot \nabla T)_{\mathrm{S}}-\lambda_{\mathrm{L}}(\mathbf{n} \cdot \nabla T)_{\mathrm{L}}
$$

Mass balance equation:

$$
\left(C_{\mathrm{L}}-C_{\mathrm{S}}\right) \frac{\partial f}{\partial t}\left(\mathbf{n} \cdot \mathbf{e}_{y}\right)=-D_{\mathrm{L}}(\mathbf{n} \cdot \nabla C)_{\mathrm{L}}
$$

These equations were non-dimensionalized as the same way as the liquid phase governing equations. The interface position was determined at each time step by coupling the pseudo binary phase diagram of $\operatorname{In}_{x} \mathrm{Ga}_{1-x} \mathrm{Sb}^{11)}$ with these balance equations. Position of the solution-feed interface was also determined by the same procedure.

As for the initial conditions, the complete molten state of $\mathrm{InSb}$ was regarded as the initial state in the simulation, and therefore, the initial $\mathrm{GaSb}$ concentration in the solution was taken zero. The initial temperature of the solution was selected as $525^{\circ} \mathrm{C}$, which is the melting point of InSb.

Numerical simulations were carried out under both $1 \mathrm{G}$ (Earth's gravitational constant) and a microgravity level of $10^{-4} \mathrm{G}$ that corresponds to a typical average gravity level observed on the ISS.

\section{Results and discussion}

Heat transfer in the ampoule was first investigated. The time-evolution of computed temperature at the centers of the melt-crystal interfaces under $1 \mathrm{G}$ was shown in Fig. 4. As seen, during the first $0.5 \mathrm{~min}$ heating time, temperature rapidly increased since the ampoule was heated until the boundaries of the computational domain reached at the target temperature as shown in Fig. 1(b). After that, they gradually approached constant values (by conduction). The difference between the seed and feed temperatures was due to the furnace temperature gradient. Figure 5 shows the effect of gravity level on temperature distribution in the ampoule at the 2 nd min. In the

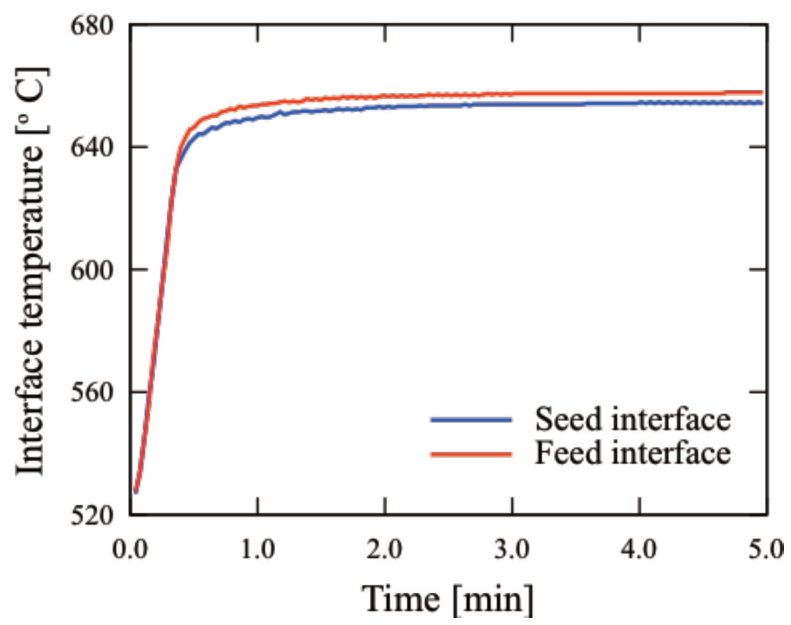

Fig. 4. Time evolution of temperature at the center of interface under normal gravity. present crystal dissolution system, the vertical temperature gradient component was dominant, and the temperature iso-contours in the solution were almost parallel to the bottom and top of the sample. Temperature distributions under normal and microgravity conditions are very similar. This shows that the heat transfer in the ampoule at the constant temperature gradient was not sensitive to the changes at the gravity levels.

In order to predict which transport phenomena is dominant in the $\operatorname{In}_{x} \mathrm{Ga}_{1-x} \mathrm{Sb}$ solution, the relative contributions of thermal and solutal convections in the solution were estimated by calculating the characteristic dimensionless numbers of the system. Computed values of the thermal and solutal Grashof numbers are presented in Table 6 . Since the values of the solutal and thermal Grashof numbers are of the same order of magnitude, contributions of the temperature and concentration gradient may be assumed comparable. However, since the high temperature region was located at the top of the solution region in the present setup, one may assume that the vertical component of thermal convection is weaker than that of solutal convection.

Computed values of the Rayleigh numbers, that describe the relationship between buoyancy and viscosity in the solution, are given in Table 7. The solutal Rayleigh number is much larger than the thermal Rayleigh number, and thus indicating that convection in the $\operatorname{In}_{x} \mathrm{Ga}_{1-x} \mathrm{Sb}$ solution affects solutal transport strongly.

Time evolution of the dissolution lengths of GaSb at both the seed and feed are shown in Fig. 6. For comparison, both

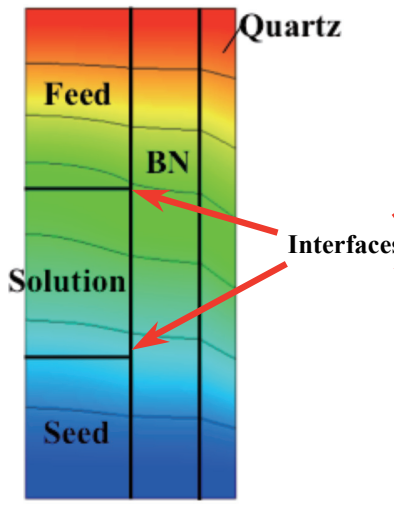

(a) $1 \mathrm{G}$

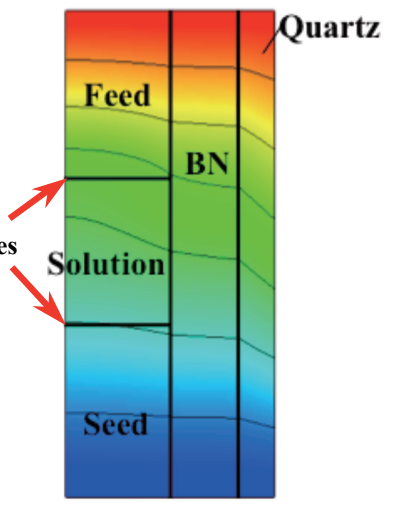

(b) $10^{-4} \mathrm{G}$

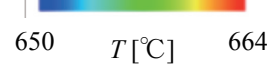

Fig. 5. Temperature distribution in the ampoule at 2 minutes.

Table 6. Thermal and solutal Grashof numbers under normal gravity.

\begin{tabular}{llc}
\hline Dimensionless number & Definition & Value \\
\hline Thermal Grashof number $\left(G r_{\mathrm{T}}\right)$ & $g \beta_{\mathrm{T}} \Delta T L^{3} / v^{2}$ & $1.3 \times 10^{5}$ \\
Solutal Grashof number $\left(G r_{\mathrm{C}}\right)$ & $g \beta_{\mathrm{C}} \Delta C L^{3} / v^{2}$ & $4.6 \times 10^{5}$ \\
\hline
\end{tabular}

Table 7. Thermal and solutal Rayleigh numbers under normal gravity.

\begin{tabular}{lcc}
\hline Dimensionless number & Definition & Value \\
\hline Thermal Rayleigh number $\left(R a_{\mathrm{T}}\right)$ & $G r_{\mathrm{T}} \cdot P r$ & $2.5 \times 10^{3}$ \\
Solutal Rayleigh number $\left(R a_{\mathrm{C}}\right)$ & $G r_{\mathrm{C}} \cdot S c$ & $6.4 \times 10^{6}$ \\
\hline
\end{tabular}


the numerical simulation and experimental results are presented. Comparison of the dissolution lengths clearly shows the effect of gravity on segregation. Results shown in Fig. 6 can be summarized as follows. The computed dissolution length at the seed under normal gravity is in a good agreement with experiment ${ }^{8)}$ while the computed length for the feed overestimates the experimental values. Under normal gravity, the dissolution length at the seed was quite large compared with that at the feed as seen in the in-situ observation $^{7}$ by the X-ray penetration method and also in the computed values. Under microgravity, however, the dissolution lengths at the seed and the feed were very close to each other (dashed lines in the middle) due to the suppression of natural convection as expected; dissolution at the seed was reduced while that in the feed was enhanced. It is noted that the slope of the computed values under microgravity change gradually, with no sudden changes. It is also important to note that at the termination time of $5 \mathrm{~min}$, while the dissolution lengths under the normal gravity approach constant values, the lengths under microgravity continue to increase. This clearly shows that the saturation time of solution under microgravity may be longer than that under normal gravity, which is important for the growth process.

To discuss the relative contributions of convection and diffusion in the solution to the dissolution of GaSb, the snapshots of computed flow velocity and GaSb concentration fields at $0.5,1,2$ and 5 min were summarized in Table 8. In the column that presents the results under normal gravity, the velocity vectors colored by the magnitude are shown on left, and the contours of $\mathrm{GaSb}$ concentration on right. In the column presenting the results under the microgravity level of $10^{-4} \mathrm{G}$, only the contours of GaSb concentration are shown since the magnitudes of flow velocity were very small and diffusion was dominant in the solution. At 0.5 and 1 mins, under normal gravity, a strong convection develops in the solution near the solution-seed interface and a plume structure is clearly seen in the concentration field because the density of $\mathrm{GaSb}$ is smaller than that of $\operatorname{In}_{0.5} \mathrm{Ga}_{0.5} \mathrm{Sb}$. At the initial stage, under normal gravity, the strong upward flow velocity appeared, which enhanced the GaSb transport in the center of

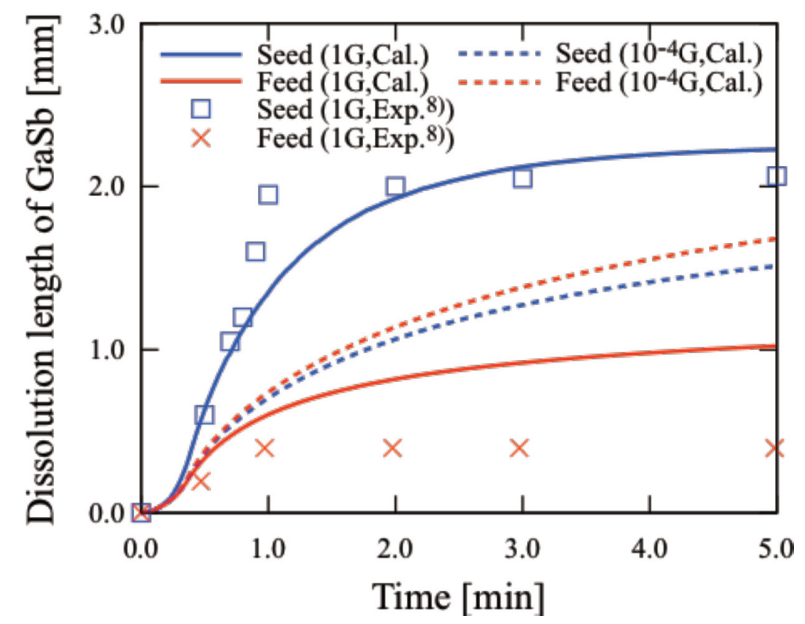

Fig. 6. Effect of the gravity level on time development of the dissolution length of GaSb. the solution. The dissolution length of GaSb was significantly increased at the seed. Then, the concentration of GaSb approached a constant value and the solution was saturated at the 5 th $\min$, the convection became weaker.

Under microgravity on the other hand, the concentration iso-contours were parallel near the seed and feed interfaces, showing that the dissolved GaSb was transported only by diffusion, and so the dissolution length of GaSb slowly increased. The concentration gradient remained constant at the 5 th min. Although diffusion was also dominant near the feed under normal gravity, its effect on dissolution was weak since the downward transport of lighter GaSb was suppressed by gravity. Therefore, the dissolution lengths under microgravity became larger compared with those under normal gravity. Under microgravity, convection was not notable and the dissolution length was linearly related to the crystal interface temperature since the solutal transport was not suppressed.

The interface positions between the InGaSb solution and the solid crystals were affected by gravity, however, the heights of saturated InGaSb solution were comparable under the both gravity levels because diffusion was dominant at the end of dissolution process. The preliminary experiment results can apply to the setup of ISS space experiment by considering the gravity effect on the initial condition of growth process after dissolution process.

\section{Conclusions}

The numerical simulation code for the dissolution process of $\mathrm{GaSb}$ into the InSb melt was developed and it was useful for not only the explanation of preliminary space experimental results but also the setup of space experiment on the ISS. From the numerical results under normal and microgravity conditions, the following conclusions were led:

- Under normal gravity, the dissolved GaSb from the seed crystal is transported into the InSb melt by solutal convection, and the dissolution from the feed is dominated by diffusion. On the other hand, under microgravity, natural convection is significantly suppressed and diffusion is dominant in the dissolution of both the feed and seed materials. Therefore, the dissolution of $\mathrm{GaSb}$ into the InSb melt is significantly affected by the solutal convection.

- Dissolution at the seed is enhanced by natural convection under $1 \mathrm{G}$ although the temperature of the seed is lower than that of the feed. Under microgravity, the contribution of solutal convection is not significant, and the feed crystal dissolves faster than the seed since the temperature is higher at this section. Microgravity, with suppressed convection, hardly affects the solutal transport, and the amount of dissolution is linearly related to the crystal interface temperature.

\section{Acknowledgments}

This work was financially supported by a Grant-in-Aid for 
Trans. JSASS Aerospace Tech. Japan Vol. 10, No. ists28 (2012)

Table 8. The time evolutions of flow velocity and GaSb concentration fields in the solution. The magnitudes of maximum flow velocity were 3.6 $\mathrm{mm} / \mathrm{s}$ at $0.5 \mathrm{~min}, 2.35 \mathrm{~mm} / \mathrm{s}$ at $1 \mathrm{~min}, 1.17 \mathrm{~mm} / \mathrm{s}$ at $2 \mathrm{~min}$ and $0.38 \mathrm{~mm} / \mathrm{s}$ at $5 \mathrm{~min}$, respectively.

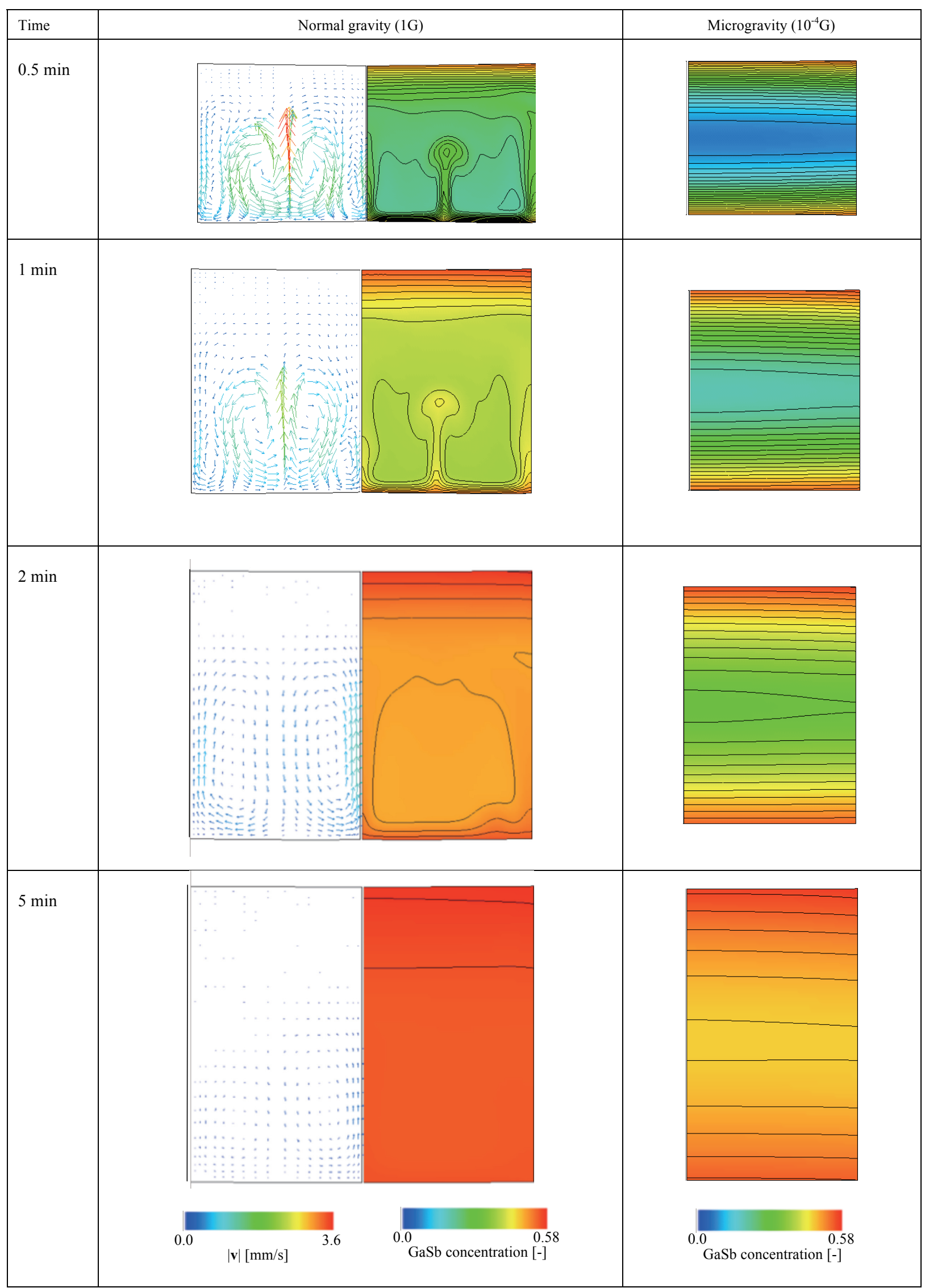


Scientific Research (B) (no.22360343) from the Ministry of Education, Culture, Sports, Science and Technology of Japan.

\section{References}

1) Murakami, N., Arafune, K., Koyama, T., Kumagawa, M. and Hayakawa, Y.: Measurement of Growth Rate by Thermal Pulse Technique and Growth of Homogeneous $\operatorname{In}_{x} \mathrm{Ga}_{1-x} \mathrm{Sb}$ Bulk Crystals, J. Crystal Growth, 275 (2005), pp.433-439.

2) Dutta, P. S. and Ostrogorsky, A. G.: Suppression of Cracks in $\mathrm{In}_{x} \mathrm{Ga}_{1-x} \mathrm{Sb}$ Crystals through Forced Convection in the Melt, $J$. Crystal Growth, 194 (1998), pp.1-7.

3) Hayakawa, Y., Okano, Y., Hirata, A., Imaishi, N., Kumagiri, Y Zhong, X., Xie, X., Wu, F., Liu, H., Yamaguchi, T. and Kumagawa, M.: Experimental and Numerical Investigations on Dissolution and Recrystallization Processes of $\mathrm{GaSb} / \mathrm{InSb} / \mathrm{GaSb}$ under Microgravity and Terrestrial Conditions, J. Crystal Growth, 213 (2000), pp.40-50.

4) Okitsu, K., Hayakawa, Y., Hirata, A., Fujiwara, S., Okano, Y., Imaishi, N., Yoda, S., Oida, T., Yamaguchi, T. and Kumagawa, M.: Gravitational Effect on Mixing and Growth Morphology of an In0.5Ga0.5Sb System, Cryst. Res. Technol., 31 (1996), pp.969-978.

5) Okitsu, K., Hayakawa, Y., Yamaguchi, T., Hirata, A., Fujiwara, S., Okano, Y., Imaishi, N. and Yoda, S.: Melt Mixing of the $0.3 \mathrm{In} / 0.7 \mathrm{GaSb} / 0.3 \mathrm{Sb}$ Solid Combination by Diffusion under Microgravity, Jpn. J. Appl. Phys., 36 (1997), pp.3613-3619.

6) Hayakawa, Y., Hikida, T., Mori, H., Konno, A., Chen, C. H., Arafune, K., Kawai, H., Koyama, T., Momose, Y., Ozawa, T. and Aoki, T.: In situ Observation of Composition Profiles in the Solution by X-ray Penetration Method, J. Crystal Growth, 310 (2008), pp.1487-1492.

7) Rajesh, G., Arivanandhan, M., Mori, H., Aoki, T., Koyama, T., Momose, Y., Tanaka, A., Ozawa, T, Inatomi, Y. and Hayakawa, Y.: In-situ Observations of Dissolution Process of GaSb into InSb Melt by X-ray Penetration Method, J. Crystal Growth, 312 (2010), pp.2677-2682.

8) Rajesh, G., Arivanandhan, M., Suzuki, N., Tanaka, A., Morii, H., Aoki, T., Koyama, T., Momose, Y., Ozawa, T., Inatomi, Y., Takagi, Y., Okano, Y. and Hayakawa, Y.: Effects of solutal convection on the dissolution of GaSb into InSb melt and solute transport mechanism in InGaSb solution: Numerical simulations and in-situ observation experiments, J. Crystal Growth, 324 (2011), pp.157-162.

9) Stringfellow, G. B.: Calculation of Ternary Phase Diagram of III-V Systems, J. Phys. Chem. Solids, 33 (1972), pp.665-677.

10) Sato, Y., Nishizuka, T., Takamizawa, T., Yamamura, T. and Waseda, Y.: Viscosity of Molten GaSb and InSb, Int. J. Thermophysics, 23 (2002), pp.235-243.

11) Stelian, C., Duffar, T. and Nicoara, I.: Comparison between Numerical Simulation and Experimental Measurement of Solute Segregation during Directional Solidification, J. Crystal Growth, 255 (2003), pp.40-51. 